\title{
RESEARCH
}

Open Access

\section{Public support for healthy supermarket initiatives focused on product placement: a multi-country cross-sectional analysis of the 2018 International Food Policy Study}

Clara Gómez-Donoso ${ }^{1,2}$, Gary Sacks ${ }^{3}$, Lana Vanderlee ${ }^{4}$, David Hammond ${ }^{5}$, Christine M. White ${ }^{5}$, Claudia Nieto ${ }^{6}$, Maira Bes-Rastrollo ${ }^{1,2}$ and Adrian J. Cameron ${ }^{3^{*}}$ (i)

\begin{abstract}
Background: Food retail environments have an influential role in shaping purchasing behavior and could contribute to improving dietary patterns at a population level. However, little is known about the level of public support for different types of initiatives to encourage healthy food choices in supermarkets, and whether this varies across countries or context. The current study aimed to explore the level of support for three potential supermarket initiatives focused on product placement across five countries, and factors that may influence this support.

Methods: A total of 22,264 adults from Australia, Canada, Mexico, the United Kingdom and the United States (US) provided information on support for three supermarket initiatives related to product placement (targeting product positioning: 'checkouts with only healthy products', 'fewer end-of-aisle displays containing unhealthy foods or soft drinks' or availability: 'more shelf space for fresh and healthier foods') as part of the online 2018 International Food Policy Study. The proportion of respondents that supported each initiative was assessed across countries, and multivariable logistic regression analyses were conducted to evaluate the influence of sociodemographic factors on support.

Results: The initiative that received the highest support was 'more shelf space for fresh and healthier foods': 72.0\% [95\% Cl 71.3-72.7], whereas 'checkouts with only healthy products' received the lowest support: 48.6\% [95\% Cl 47.8-49.4]. The level of support differed between countries ( $p<0.001$ for all initiatives), with the US generally showing the lowest support and Mexico the highest. Noteworthy, in the overall sample, there was not much opposition to any of the initiatives (2.514.2\%), whereas there was a large proportion of neutral responses (25.5-37.2\%). Respondents who were older, female, highly educated, and those who reported having more nutrition knowledge tended to be more supportive, with several differences between countries and initiatives.

Conclusions: Most people in the assessed five countries showed a generally high level of support for three placement initiatives in supermarkets to encourage healthy food choices. Support varied by type of initiative (i.e., product positioning or availability) and was influenced by several factors related to country context and sociodemographic characteristics. This evidence could prompt and guide retailers and policy makers to take stronger action to promote healthy food choices in stores.
\end{abstract}

Keywords: Supermarket, Retail, Food environment, Attitudes, Diet, Food policy

\footnotetext{
* Correspondence: adrian.cameron@deakin.edu.au

${ }^{3}$ Global Obesity Centre (GLOBE), Institute for Health Transformation, Deakin University, 221 Burwood Highway, Burwood VIC, Geelong 3125, Australia

Full list of author information is available at the end of the article
}

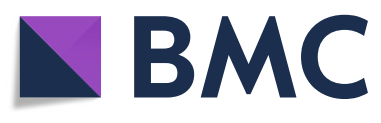

(c) The Author(s). 2021 Open Access This article is licensed under a Creative Commons Attribution 4.0 International License, which permits use, sharing, adaptation, distribution and reproduction in any medium or format, as long as you give appropriate credit to the original author(s) and the source, provide a link to the Creative Commons licence, and indicate if changes were made. The images or other third party material in this article are included in the article's Creative Commons licence, unless indicated otherwise in a credit line to the material. If material is not included in the article's Creative Commons licence and your intended use is not permitted by statutory regulation or exceeds the permitted use, you will need to obtain permission directly from the copyright holder. To view a copy of this licence, visit http://creativecommons.org/licenses/by/4.0/. The Creative Commons Public Domain Dedication waiver (http://creativecommons.org/publicdomain/zero/1.0/) applies to the data made available in this article, unless otherwise stated in a credit line to the data. 


\section{Introduction}

Unhealthy diets represent one of the leading preventable risk factors for chronic diseases worldwide [1]. Many food retail environments currently encourage and promote unhealthy food choices, likely contributing to the increasing epidemic of obesity and diet-related chronic diseases [2-4]. Globally, large supermarket chains have become dominant players in the food retail industry, replacing traditional food markets and small specialized stores [5]. Marketing practices within supermarkets such as product displays, placement and promotions strongly influence food accessibility, availability, affordability and desirability, which in turn play an important role in shaping food preferences and purchasing behavior [6-11]. Multiple studies across a range of countries have shown how supermarket environments currently favor the promotion of less healthy food despite recommendations that these foods should only be consumed occasionally and in small amounts [12-19]. Even more worrying is that public health strategies such as front-of-pack nutrition labelling could be undermined by current retail food environments predominantly driving consumption of unhealthy foods. Given that supermarkets are the setting for more than $50 \%$ of all food purchased globally [20], and that more than half of consumers' grocery store purchasing decisions are unplanned [21, 22], in-store environmental initiatives that promote healthy food choices have significant potential to improve dietary-related behaviors and lower the risk of disease at the population level [23-25].

Despite the influence of food environments on purchasing intentions and behaviors, policy actions to address diet-related chronic diseases have often focused on the individual level [26-28]. The limited implementation of policies to create healthier food environments may be due to lack of popular support for fiscal and regulatory interventions, which are sometimes deemed intrusive to individuals' freedom of choice [29-34]. However, there is evidence showing high public support for nudges [35-38], which apply behavioral science approaches to make small, usually unnoticed, environmental changes that steer people in particular directions. Changes to food retail environments that impact the way choices are presented to consumers (i.e., choice architecture) are well-recognized examples of nudges that target non-deliberative decisions [39]. Although most nudges in modern supermarkets currently promote purchasing of less healthy products [14-19], they could equally promote the purchasing of healthier foods. Systematic reviews have indeed shown that healthy food retail interventions targeting the in-store supermarket environment have led to improvements in the healthiness of consumer purchases $[8,40]$. These interventions have mainly focused on changes regarding product placement, such as altering the position or availability of certain products. Examples include increasing the range or number of healthy options or avoiding placement of less healthy options in prominent locations, like checkout lanes, end-of-aisle or island bin displays.

Previous studies in Europe, the United Kingdom (UK) and the United States (US) have demonstrated widespread customer support for health-promoting supermarket nudges related to product positioning (e.g., changing the shelf location of sugar-sweetened beverages, placing most healthy foods in a prominent location, and requiring sweet-free checkouts) [36-38]. Nevertheless, few studies have examined the public support for product placement supermarket interventions focused on both positioning and availability across different countries. The level of public support for particular initiatives is recognized as playing a pivotal role in determining the extent to which evidence is implemented into policy [41, 42]. Moreover, increased understanding of the level of public support for various initiatives in different contexts and the opportunities to influence support could guide food retailers' efforts to shape food choices. Accordingly, this study aimed to evaluate the level of public support for several product placement supermarket initiatives that were selected based on policy relevance, feasibility for retailers or their likely public health impact, and the sociodemographic factors associated with support within and between countries.

\section{Methods}

\section{Study design and participants}

This study used data from the 2018 International Food Policy Study (IFPS), an annual, cross-sectional study conducted in Australia, Canada, Mexico, the UK, and the US. The IFPS was designed to evaluate the impact of public health nutrition interventions on dietary patterns and policy-relevant behaviors across countries that are introducing novel regulations in the area of food policy (e.g., food retail interventions, price/taxation, food packaging and labelling, food marketing and others). A selfadministered web-based survey was completed in November-December 2018 by adults aged 18+ in each of the five countries, and collected information on sociodemographic characteristics, diet and food policy-related attitudes, behaviors and knowledge. Participants were recruited through the Nielsen Consumer Insights Global Panel and their partners' panels (https://www.nielsen. com/us/en/about-us/panels/) using non-probability sampling methods based on quota requirements for age and sex to facilitate recruitment of a diverse sample that approximated the corresponding proportions in the general population of each country. Eligible panelists (i.e., individuals aged $18+$ years living within the target countries) were invited by email to complete the survey. After screening for eligibility and quota requirements, all potential respondents were provided with information 
about the study and were asked to provide consent before participating. A total of 439,821 invitations were sent to panelists; of which $7.7 \%$ accessed the survey link and $6.5 \%$ completed the 2018 IFPS survey $(n=28,684)$. Respondents provided consent before completing the survey and were incentivized in accordance with their panel's existing reward structure (e.g., points-based or monetary rewards, or chances to win prizes). The study was reviewed by and received ethics clearance through a University of Waterloo Research Ethics Committee (Office of Research Ethics \#30829) prior to data collection. A full description of the study methods, including annual surveys conducted in each of the five countries, is available elsewhere [43].

\section{Measures}

Support for supermarket initiatives focused on product placement

The current study analyzed survey questions on respondents support for three supermarket initiatives pertaining to product placement: 1) Checkouts with only healthy products (e.g., no soft drinks, chocolate, confectionery) ('checkouts'), 2) Fewer end-of-aisle displays containing unhealthy foods or soft drinks ('end-of-aisle'), and 3) More shelf space for fresh and healthier foods such as fruits and vegetables ('shelf space'). These initiatives were classified using the TIPPME framework (Typology of Interventions in Proximal Physical Micro-Environments) [44], which was developed to reliably classify and describe nudging interventions based on altering small aspects of the environment to change health-related behavior at the population level. Accordingly, the initiatives were classified as product positioning interventions (initiatives limiting or banning unhealthy food from highly visible places: 'end-of-aisle' and 'checkouts') or availability interventions (initiatives increasing the range or number of healthy food: 'shelf space'). Those included were mainly selected based on evidence on the effect of nudges on purchasing behavior ('end-of-aisle') [7, 45] and evidence that supermarket retailers can successfully implement the nudge ('checkouts' and 'shelf space') [46-49].

To reduce survey length and minimize respondent burden, respondents were shown a randomly selected subset of two of the three supermarket measures. Policy support was measured by asking respondents 'Would you support or oppose the following practices in supermarkets...' and completing the question with each of the actions stated above, shown in a randomized order. Respondents could select either 'support', 'neutral', 'oppose', 'don't know' or 'refuse to answer'. These responses were re-categorized into a binary variable for analysis (support/other), where responses of 'support' were categorized as 'support', and responses of 'neutral' and 'oppose' were categorized as 'other'. Responses of 'don't know' and 'refuse to answer' were excluded $(n=560)$. There were no missing data among respondents.

\section{Sociodemographic variables}

Self-reported sociodemographic variables collected in the survey included age, sex, ethnicity, education, and body mass index (BMI). For the current study, age was categorized into four age groups that were also used to facilitate recruitment of a diverse sample: 18-29, 30-44, $45-64$, and $65+$ years. Ethnicity was categorized as 'majority' (if respondents identified as white "only" in Canada, UK and USA, English speaking in Australia or non-indigenous in Mexico), 'minority' (other valid responses), or 'not stated'. Education level was categorized as 'low' (i.e., secondary school completion or lower), 'medium' (i.e., some post-secondary qualifications), or 'high' (i.e., university degree or higher) according to country-specific criteria related to the highest level of formal education attained, or 'not stated'. Further details about country-specific criteria and question wording can be found at http://foodpolicystudy.com/methods. Selfreported height and weight data were used to calculate BMI, which was categorized as 'underweight' $(<18.5 \mathrm{~kg} /$ $\mathrm{m}^{2}$ ), 'normal weight' $\left(18.5-24.9 \mathrm{~kg} / \mathrm{m}^{2}\right)$, 'overweight' $\left(25.0-29.9 \mathrm{~kg} / \mathrm{m}^{2}\right)$, 'obesity' $\left(\geq 30.0 \mathrm{~kg} / \mathrm{m}^{2}\right)$, or 'missing/ not stated'. Self-reported nutrition knowledge was measured by asking 'How would you rate your nutrition knowledge?'. Responses of 'not at all knowledgeable' and 'a little knowledgeable' were categorized as 'none/low', responses of 'somewhat knowledgeable' were categorized as 'moderate', and responses of 'very knowledgeable' and 'extremely knowledgeable' were categorized as 'high'. For education, ethnicity, BMI and nutrition knowledge, responses of 'don't know' and 'refuse to answer' were recategorized as 'not stated'. Participants in this category, as well as missing data (except for BMI), were excluded from the logistic regression analyses $(n=376)$ but included when reporting the proportion of respondents that support supermarket initiatives and descriptive characteristics of study participants.

\section{Dietary variables}

Respondents' dietary behavior was assessed through the following self-reported measures: sugar-sweetened beverage (SSB) and fruits and vegetables (FV) consumption.

The Beverage Frequency Questionnaire (BFQ), a 7-day food record that assesses consumption for 24 types of drinks [50], was used to derive weekly SSB consumption. For each beverage category, respondents reported the number of drinks they had consumed over the past week and the usual portion size, using examples of beverages and category-specific images of beverage containers to prompt recognition. The BFQ was adapted for each country to provide product examples and typical beverage 
container sizes commonly sold in each market. Total volume for each beverage category of interest was calculated by multiplying the number of drinks consumed in the previous 7 days by the usual serving size selected for that category. Total SSB consumption included intake of regular soda, sweetened fruit drinks, flavored waters, sports drinks, energy drinks, flavored milk, specialty coffees like mochas or frappucinos, sweetened smoothies, protein shakes and drinkable yogurt. The total SSB consumption variable was categorized into three groups: 'none', 'low' (i.e., below the mean) and 'high' (i.e., above the mean) according to the weighted mean of weekly SSB consumption amongst consumers in the analytical sample $(1888 \mathrm{~mL})$.

As part of an assessment of general health status, respondents were asked the number of times they consumed fruit and vegetables (excluding non-100\% fruitjuice and fried potatoes) per day, week or month during the past 30 days. This information was used to compute a daily FV consumption variable where, based on global recommendations on healthy diet [51], intake lower than 3 servings/day was categorized as 'low', intake between 3 and less than 5 as 'moderate' and intake equal to or higher than 5 as 'high'.

\section{Statistical analyses}

Data were weighted with post-stratification sample weights constructed using a raking algorithm with country-specific population estimates from census data based on age group, sex, region, ethnicity (except in Canada) and education (except in Mexico). A detailed explanation of survey weights can be found at http:// foodpolicystudy.com/methods (International Food Policy Study: Technical Report 2018). These sample weights were used throughout the analysis in order to minimize the influence of differential non-response and selection bias on the representativeness of findings.

Descriptive statistics were used to summarize the sociodemographic characteristics of the sample. The proportion of 'support', 'neutral' and 'oppose' responses regarding the three supermarket interventions was determined overall (i.e., as a total sample) and by country. The percentage of overall supermarket action support using the binary support variable was also assessed for each country.

Multivariable logistic regression models were fitted using binary support for each supermarket initiative among respondents to explore associations between sociodemographic variables and support. Explanatory variables introduced in models included sex, age, education, BMI classification and self-reported nutrition knowledge. These were selected a priori to be included as covariates in the logistic regression models based on existing literature [32, 33]. Dietary behaviors, including SSB and FV consumption, were assessed as covariates in supplementary analyses. Adjusted OR (95\% CI) of support for each supermarket initiative are presented adjusted for all other variables. This analysis was completed among the total sample and among each country individually. Two-way interactions between country and each of the covariates were assessed by including each interaction in the model and performing a contrast analysis.

Statistical significance was set at the conventional 0.05 level. Analyses were performed using Stata version 14.0 (StataCorp, College Station, TX).

\section{Results}

\section{Sample characteristics}

A total of 28,684 respondents completed the 2018 IFPS survey. Respondents were excluded for the following reasons: region was missing, ineligible or had an inadequate sample size (i.e., respondents from the 3 Canadian territories); invalid response to a data quality question; survey completion time under $15 \mathrm{~min}$; and/or invalid responses to at least three of 16 open-ended measures $(n=5860)$. The analytic sample included 22 , 824 respondents. A sub-sample of 22,264 respondents (Australia: $n=4004$; Canada: $n=4288$; Mexico: $n=4082$; United Kingdom: $n=5367$; United States: $n=4523$ ) were included in the current analysis after excluding those responding 'don't know' or 'refuse to answer' regarding support for supermarket initiatives.

Weighted sample characteristics for each country are described in Table 1. The weighted mean age $( \pm$ SD) among all participants was $46( \pm 20)$ years, and the proportions of male and female respondents were approximately equal across the five countries. Among the overall sample, the majority of respondents reported having low education level and some nutrition knowledge, and were classified as having self-reported BMI between 18.5 and 24.9. As expected, with each participant randomly asked about their support for only two of the three supermarket initiatives in an attempt to restrict overall survey length, almost no variation was seen in unweighted sample characteristics for the subsets of respondents that answered each question (see Additional file 1).

\section{Support for supermarket initiatives focused on product placement}

The proportion of respondents that supported each supermarket initiative by country is shown in Fig. 1, and is reported in more detail in Additional file 2 (i.e., proportion of neutral and opposition responses also shown). The level of support was relatively high for all initiatives, ranging between $48.6-72.0 \%$ across the total sample. The most supported initiative overall and across different countries was 'more shelf space for fresh and 
Table 1 Weighted sociodemographic characteristics of participants in five countries (expressed as n (\%), unless otherwise stated) from the International Food Policy Study $2018(n=22,264)$

\begin{tabular}{|c|c|c|c|c|c|c|}
\hline & $\begin{array}{l}\text { Overall } \\
n=22,264\end{array}$ & $\begin{array}{l}\text { Australia } \\
n=4004\end{array}$ & $\begin{array}{l}\text { Canada } \\
n=4288\end{array}$ & $\begin{array}{l}\text { United Kingdom } \\
n=5367\end{array}$ & $\begin{array}{l}\text { United States } \\
n=4523\end{array}$ & $\begin{array}{l}\text { Mexico } \\
n=4082\end{array}$ \\
\hline \multicolumn{7}{|l|}{ Sex } \\
\hline Male & $10,909(48.7)$ & 1954 (48.8) & $2123(49.5)$ & 2614 (48.7) & 2203 (48.7) & $1947(47.7)$ \\
\hline Female & $11,355(51.3)$ & $2050(51.2)$ & 2165 (50.5) & 2753 (51.3) & $2320(51.3)$ & $2135(52.3)$ \\
\hline Age, mean (SD) & $46.0(20.1)$ & 46.5 (19.6) & $48.2(21.9)$ & $48.1(20.4)$ & $46.9(20.3)$ & $39.3(18.3)$ \\
\hline \multicolumn{7}{|l|}{ Age group } \\
\hline 18-29years old & 4965 (22.3) & $877(21.9)$ & $853(19.9)$ & $1041(19.4)$ & $954(21.1)$ & $1233(30.2)$ \\
\hline 30-44 years old & $5878(26.4)$ & $1057(26.4)$ & 1055 (24.6) & $1310(24.4)$ & $1140(25.2)$ & 1318 (32.3) \\
\hline 45-59years old & $5788(26.0)$ & $981(24.5)$ & $1111(25.9)$ & $1406(26.2)$ & $1149(25.4)$ & $1147(28.1)$ \\
\hline $60+$ years old & $5633(25.3)$ & 1089 (27.2) & 1269 (29.6) & $1610(30.0)$ & $1280(28.3)$ & $384(9.4)$ \\
\hline \multicolumn{7}{|l|}{ Ethnicity } \\
\hline Majority & $17,611(79.1)$ & 3015 (75.3) & $3293(76.8)$ & $4728(88.1)$ & 3406 (75.3) & 3159 (77.4) \\
\hline Minority & 4386 (19.7) & $977(24.4)$ & $858(20.0)$ & $596(11.1)$ & $1094(24.2)$ & $861(21.1)$ \\
\hline Not stated & $267(1.2)$ & $12(0.3)$ & $137(3.2)$ & $43(0.8)$ & $23(0.5)$ & $62(1.5)$ \\
\hline \multicolumn{7}{|l|}{ Education } \\
\hline Low & $9484(42.6)$ & 1666 (41.6) & $1809(42.2)$ & $2576(48.0)$ & $2632(58.2)$ & 812 (19.9) \\
\hline Medium & $4943(22.2)$ & $1297(32.4)$ & 1424 (33.2) & 1229 (22.9) & 448 (9.9) & $535(13.1)$ \\
\hline High & 7770 (34.9) & $1033(25.8)$ & $1038(24.2)$ & $1530(28.5)$ & 1438 (31.8) & 2731 (66.9) \\
\hline Not stated & $67(0.3)$ & $8(0.2)$ & $17(0.4)$ & $32(0.6)$ & $5(0.1)$ & $4(0.1)$ \\
\hline \multicolumn{7}{|l|}{ BMl } \\
\hline$<18.5$ & $668(3.0)$ & $124(3.1)$ & $142(3.3)$ & $161(3.0)$ & $158(3.5)$ & $86(2.1)$ \\
\hline $18.5-24.9$ & 7748 (34.8) & $1441(36.0)$ & $1432(33.4)$ & $1852(34.5)$ & 1375 (30.4) & $1633(40.0)$ \\
\hline $25-30$ & $6167(27.7)$ & $1053(26.3)$ & 1226 (28.6) & 1428 (26.6) & $1257(27.8)$ & 1208 (29.6) \\
\hline$\geq 30$ & 4609 (20.7) & $833(20.8)$ & $1029(24.0)$ & $896(16.7)$ & $1226(27.1)$ & $633(15.5)$ \\
\hline Missing/not stated & 3072 (13.8) & $553(13.8)$ & $459(10.7)$ & $1030(19.2)$ & $507(11.2)$ & $522(12.8)$ \\
\hline \multicolumn{7}{|l|}{ Nutrition knowledge } \\
\hline None/low & 8416 (37.8) & $1457(36.4)$ & 1454 (33.9) & $2581(48.1)$ & 1569 (34.7) & 1359 (33.3) \\
\hline Moderate & $9462(42.5)$ & $1654(41.3)$ & $1908(44.5)$ & 1911 (35.6) & $1841(40.7)$ & $2147(52.6)$ \\
\hline High & $4275(19.2)$ & $873(21.8)$ & $892(20.8)$ & $848(15.8)$ & $1090(24.1)$ & $567(13.9)$ \\
\hline Not stated & $111(0.5)$ & $20(0.5)$ & $34(0.8)$ & $27(0.5)$ & $23(0.5)$ & $9(0.2)$ \\
\hline
\end{tabular}

healthier foods', and the least supported initiative was 'checkouts with only healthy products'. Consistent with the support trend, the initiative with the highest level of opposition overall was 'checkouts with only healthy products' and the initiative with the lowest opposition was 'more shelf space for fresh and healthier foods'. However, in general, respondents across the total sample did not show much opposition to any of the initiatives (2.5-14.2\%), and there was a large proportion of neutral responses to most initiatives (25.5-37.2\%). For instance, while the lowest support across all countries was $48.6 \%$ for checkouts with only healthy products, only $14.2 \%$ opposed to this initiative (see Additional file 2).

The level of support differed significantly between countries $(p<0.001)$. Support for all initiatives was generally lowest in the US and highest in Mexico, although between-country differences varied across initiatives. In accordance with this trend, the level of opposition was highest in the US and lowest in Mexico.

\section{Sociodemographic characteristics and support for supermarket initiatives}

Results of the multivariable logistic regression model fitted to explore associations between support and sociodemographic variables are shown in Table 2. Overall, respondents who were older, female, more highly educated and had greater self-reported nutrition knowledge tended to be more supportive. These findings remained substantially unchanged when a sensitivity analysis excluding 'neutral' responses from the 'other' (non- 


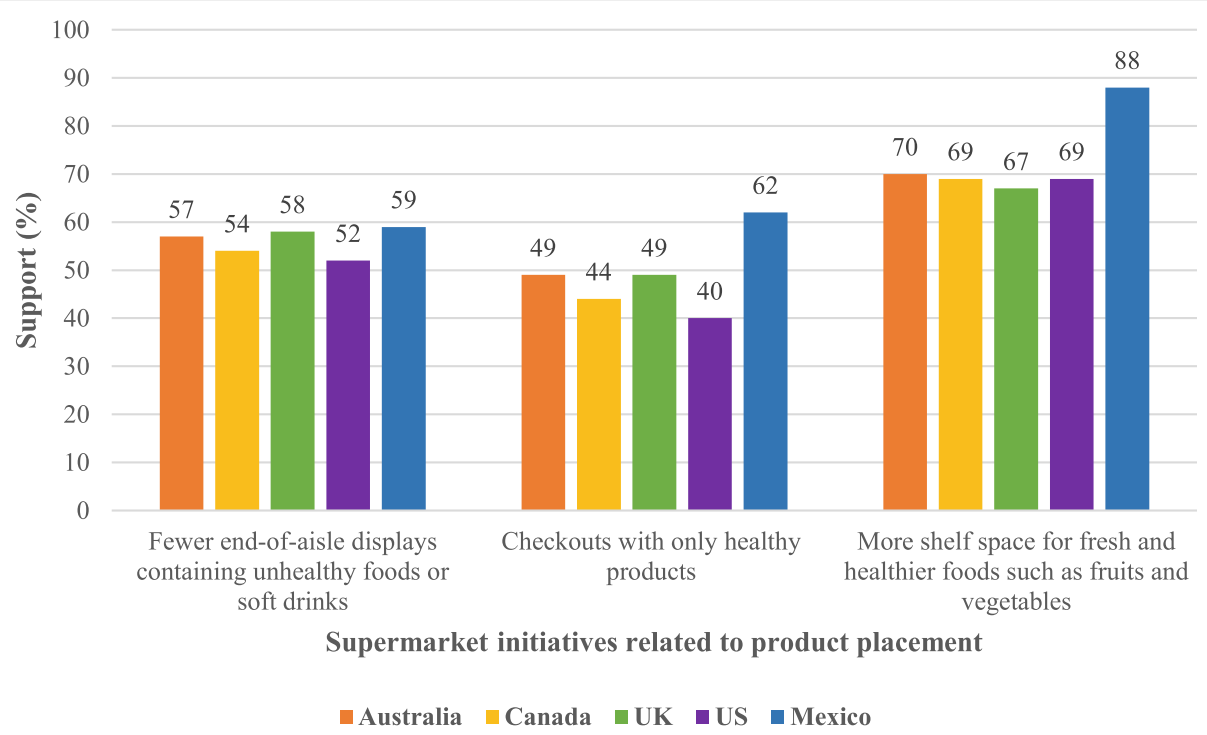

Fig. 1 Weighted proportion of respondents that support supermarket initiatives related to product placement by country. International Food Policy Study $2018(n=22,264)$

support) category was performed - data shown in Additional file 3. Respondents with healthier dietary habits (i.e., lower consumption of SSBs and higher consumption of FV) were also found to be more likely to support the three initiatives assessed - data shown in Additional file 4. Stratified analyses according to country showed that these associations differed in several respects (magnitude and statistical significance) between countries and initiatives - data shown in Additional file 5.

Statistically significant interactions $(p<0.05)$ were observed between country and both age and self-reported nutrition knowledge in relation to support for 'fewer end-of-aisle displays containing unhealthy foods or soft drinks' (i.e., associations between these covariates and support for 'fewer end-of-aisle displays containing unhealthy foods or soft drinks' differed according to country). In the case of support for 'checkouts with only healthy products', significant interactions were observed between country and both age and sex. Finally, concerning support for 'more shelf space for fresh and healthier foods', there was a statistically significant interaction between country and self-reported nutrition knowledge.

\section{Discussion}

This study assessed the level and determinants of public support for product placement interventions to encourage healthy food choices in supermarkets, with a focus on differences between and within countries. Most respondents in five countries supported the initiatives presented to them, although the level of support differed according to country and type of initiative (i.e., product positioning or availability). In line with previous evidence, initiatives that most limited freedom of choice, such as checkouts with only healthy products, generally had relatively lower support [30-36].

To our knowledge, this is the first study to explore sociodemographic differences, as well as differences between diverse countries, in relation to support for different types of product placement interventions in supermarkets. Sociodemographic characteristics of individuals, including age, sex, education, self-reported nutrition knowledge and dietary habits were found to be associated with level of support. Both the magnitude and statistical significance of these associations varied according to country, suggesting that country-level factors play an important role in public support for the assessed supermarket interventions.

\section{Differences between initiatives}

Public support was lower for more restrictive measures related to product positioning (i.e., banning or limiting unhealthy foods from dynamic promotional displays). On the other hand, the most supported initiative overall and across countries targeted availability (i.e., more shelf space for fresh and healthier foods). The same trend of support was observed among Australian respondents $(n=3767)$ in the 2017 IFPS wave (surveys in the other four countries did not include the supermarket initiative questions in 2017). In the 2017 survey wave, the highest support was also reported for more shelf space for fresh and healthier foods, with lower support for imposing restrictions on placement of unhealthy products at highly visible locations within the store, including checkouts, end-of-aisle, and island bin displays (data not shown). 
Table 2 Adjusted OR (95\% Cl) of characteristics associated with support for supermarket initiatives focused on product placement

\begin{tabular}{|c|c|c|c|c|c|c|c|}
\hline \multirow[t]{2}{*}{ Variable } & \multirow[t]{2}{*}{ Categories } & \multicolumn{2}{|c|}{$\begin{array}{l}\text { Fewer end-of-aisle displays } \\
\text { containing unhealthy foods } \\
\text { or soft drinks }\end{array}$} & \multicolumn{2}{|c|}{$\begin{array}{l}\text { More shelf space for fresh } \\
\text { and healthier foods }\end{array}$} & \multicolumn{2}{|c|}{$\begin{array}{l}\text { Checkouts with } \\
\text { only healthy products }\end{array}$} \\
\hline & & Support \% & $\mathrm{OR}^{\mathrm{a}}(95 \% \mathrm{Cl})$ & Support \% & $\mathrm{OR}^{\mathrm{a}}(95 \% \mathrm{Cl})$ & Support \% & $\mathrm{OR}^{\mathrm{a}}(95 \% \mathrm{Cl})$ \\
\hline \multirow[t]{25}{*}{ Country } & Australia & 57 & Reference & 70 & Reference & 49 & Reference \\
\hline & Canada & 54 & $0.86(0.75$ to 0.97$)$ & 69 & 0.92 (0.80 to 1.06$)$ & 44 & 0.83 (0.73 to 0.94$)$ \\
\hline & UK & 58 & 1.13 (1.00 to 1.28$)$ & 67 & 0.95 (0.83 to 1.08 ) & 49 & 1.10 (0.98 to 1.24$)$ \\
\hline & US & 52 & 0.80 (0.71 to 0.92$)$ & 69 & 0.95 (0.82 to 1.09 ) & 40 & 0.70 (0.62 to 0.80$)$ \\
\hline & Mexico & 59 & 1.19 (1.04 to 1.36$)$ & 88 & 3.58 ( 2.99 to 4.29 ) & 62 & 1.77 (1.54 to 2.03 ) \\
\hline & Canada & 54 & Reference & 69 & Reference & 44 & Reference \\
\hline & Australia & 57 & 1.17 (1.03 to 1.33$)$ & 70 & 1.09 (0.95 to 1.26$)$ & 49 & 1.20 (1.06 to 1.37$)$ \\
\hline & UK & 58 & 1.33 ( 1.17 to 1.50$)$ & 67 & 1.03 (0.90 to 1.18$)$ & 49 & 1.33 (1.17 to 1.50$)$ \\
\hline & US & 52 & 0.94 (0.83 to 1.08 ) & 69 & 1.03 (0.89 to 1.20$)$ & 40 & 0.84 (0.74 to 0.96 ) \\
\hline & Mexico & 59 & 1.39 (1.21 to 1.60$)$ & 88 & 3.91 (3.25 to 4.69 ) & 62 & 2.13 (1.85 to 2.46 ) \\
\hline & UK & 58 & Reference & 67 & Reference & 49 & Reference \\
\hline & Canada & 54 & 0.75 (0.67 to 0.86$)$ & 69 & 0.97 (0.84 to 1.11$)$ & 44 & 0.75 (0.67 to 0.85$)$ \\
\hline & Australia & 57 & 0.88 (0.78 to 1.00$)$ & 70 & $1.06(0.92$ to 1.21$)$ & 49 & 0.91 (0.81 to 1.02 ) \\
\hline & US & 52 & 0.71 (0.63 to 0.80$)$ & 69 & $1.00(0.87$ to 1.15$)$ & 40 & 0.64 (0.56 to 0.72 ) \\
\hline & Mexico & 59 & $1.05(0.92$ to 1.20$)$ & 88 & 3.78 (3.18 to 4.50 ) & 62 & 1.61 (1.41 to 1.83 ) \\
\hline & US & 52 & Reference & 69 & Reference & 40 & Reference \\
\hline & Canada & 54 & $1.06(0.93$ to 1.21$)$ & 69 & 0.97 (0.84 to 1.12 ) & 44 & 1.18 (1.04 to 1.35 ) \\
\hline & Australia & 57 & 1.24 (1.09 to 1.41$)$ & 70 & 1.06 (0.92 to 1.22$)$ & 49 & 1.43 (1.26 to 1.62$)$ \\
\hline & UK & 58 & 1.41 (1.24 to 1.59$)$ & 67 & 1.00 (0.87 to 1.15$)$ & 49 & 1.57 (1.39 to 1.78 ) \\
\hline & Mexico & 59 & 1.47 (1.29 to 1.69$)$ & 88 & 3.78 (3.17 to 4.51 ) & 62 & 2.53 (2.20 to 2.89 ) \\
\hline & Mexico & 59 & Reference & 88 & Reference & 62 & Reference \\
\hline & Canada & 54 & 0.72 (0.63 to 0.83 ) & 69 & $0.26(0.21$ to 0.31$)$ & 44 & 0.47 (0.41 to 0.54$)$ \\
\hline & Australia & 57 & 0.84 (0.73 to 0.97$)$ & 70 & 0.28 (0.23 to 0.33$)$ & 49 & 0.56 (0.49 to 0.65 ) \\
\hline & UK & 58 & 0.95 (0.84 to 1.09 ) & 67 & $0.26(0.22$ to 0.31$)$ & 49 & 0.62 (0.55 to 0.71$)$ \\
\hline & US & 52 & 0.68 (0.59 to 0.78$)$ & 69 & $0.26(0.22$ to 0.32$)$ & 40 & $0.40(0.35$ to 0.45$)$ \\
\hline \multirow[t]{4}{*}{ Age } & $18-29$ & 49 & Reference & 68 & Reference & 44 & Reference \\
\hline & $30-44$ & 53 & 1.12 (0.99 to 1.25$)$ & 70 & 1.13 (0.99 to 1.29$)$ & 51 & 1.27 (1.13 to 1.43$)$ \\
\hline & $45-59$ & 58 & 1.41 (1.25 to 1.59$)$ & 75 & 1.60 (1.38 to 1.84$)$ & 51 & 1.31 (1.16 to 1.48 ) \\
\hline & $60+$ & 64 & 1.85 (1.64 to 2.10 ) & 76 & 1.87 (1.63 to 2.16 ) & 48 & 1.28 (1.13 to 1.44$)$ \\
\hline \multirow[t]{2}{*}{ Sex } & Male & 52 & Reference & 67 & Reference & 46 & Reference \\
\hline & Female & 60 & 1.41 (1.30 to 1.53$)$ & 78 & 1.74 (1.59 to 1.91$)$ & 52 & 1.31 (1.21 to 1.42 ) \\
\hline \multirow[t]{3}{*}{ Education } & Low & 53 & Reference & 69 & Reference & 45 & Reference \\
\hline & Medium & 58 & 1.19 (1.07 to 1.32$)$ & 71 & 1.12 (1.00 to 1.26$)$ & 50 & 1.15 (1.04 to 1.28$)$ \\
\hline & High & 58 & 1.19 (1.08 to 1.31$)$ & 78 & 1.25 (1.12 to 1.39$)$ & 53 & 1.15 (1.04 to 1.26$)$ \\
\hline \multirow[t]{3}{*}{ Nutrition knowledge } & None/low & 51 & Reference & 67 & Reference & 44 & Reference \\
\hline & Moderate & 57 & 1.23 (1.12 to 1.35$)$ & 74 & 1.26 (1.14 to 1.39 ) & 49 & 1.17 (1.07 to 1.28 ) \\
\hline & High & 63 & 1.68 (1.50 to 1.88$)$ & 81 & 2.12 (1.84 to 2.43$)$ & 59 & 1.92 (1.71 to 2.15 ) \\
\hline \multirow[t]{5}{*}{ BMl } & $<18.5$ & 57 & Reference & 75 & Reference & 50 & Reference \\
\hline & $18.5-24.9$ & 51 & 0.85 (0.66 to 1.10$)$ & 73 & 0.98 (0.72 to 1.34$)$ & 45 & 0.88 (0.68 to 1.14$)$ \\
\hline & $25-30$ & 58 & 1.01 (0.91 to 1.12$)$ & 74 & 0.96 (0.85 to 1.08 ) & 50 & $1.04(0.94$ to 1.15$)$ \\
\hline & $\geq 30$ & 60 & 1.14 (1.01 to 1.27$)$ & 72 & 0.90 (0.79 to 1.03$)$ & 50 & 1.09 (0.97 to 1.22$)$ \\
\hline & Missing/not stated & 45 & 0.64 (0.56 to 0.73$)$ & 62 & 0.60 (0.52 to 0.70$)$ & 43 & 0.78 (0.68 to 0.89 ) \\
\hline
\end{tabular}

${ }^{a}$ Adjusted for all other variables listed 
Maintaining a perception of choice has been identified as being core to promoting a sense of fairness, which, together with perceived effectiveness, are among the main predictors of policy acceptability $[41,42]$. Therefore, the observed trends of higher support for initiatives targeting availability compared to support for product positioning initiatives could be a function of respondents feeling that the choice-preserving nature of nudges are compromised in product positioning interventions. Interestingly, a study that tested acceptability towards a similar nudge involving repositioning of food products (i.e., placing healthy foods at the cash register desk, while keeping unhealthy products available elsewhere in the shop) found that the majority of customers reported positive attitudes towards it [52]. This may suggest that framing more restrictive interventions in terms of both product positioning and availability could increase support for the least popular initiative in the present study (i.e. 'checkouts with only healthy products'), as it was not explicitly specified that unhealthy foods would still be available elsewhere in the store. The impact of intervention framing on public support warrants further investigation.

In agreement with the current findings, it has also been reported that acceptability varies based on intervention-specific beliefs and the targeted food type, with more support observed for healthy food-related interventions [32, 33]. Existing evidence suggests that, although strategies that discourage unhealthy high-calorie choices are actually more effective than strategies that encourage low-calorie choices, the public tends to perceive interventions that encourage low-calorie choices to be more effective, fairer, and more acceptable than those that discourage high-calorie choices [33]. Therefore, it appears that a nudge is not approved or disapproved as such, it receives approval if and to the extent that people approve of the direction in which it nudges.

\section{Differences between countries}

Support for all initiatives was generally lowest in the US and highest in Mexico, although between-country differences varied across initiatives. This pattern of results aligns with findings from previous studies showing that policy support is influenced by country-level individualist or collectivist beliefs [30]. In addition, support for healthy food interventions has been found to be related to the degree to which people attribute obesity to external factors like excessive availability of unhealthy foods $[29,32]$. The individualistic perspective that is strongly institutionalized in Western countries [53], often irrespective of government political orientation [54], could also play a role in explaining the lower level of support for environmental interventions in Mexico compared to the US. These societal and attitudinal factors have been previously identified as having more explanatory power in terms of policy support than sociodemographic characteristics and political preferences [29].

Moreover, the culture in which an individual develops will condition the acceptable and desirable norms of behavior, so the highest support in Mexico may also reflect that Mexicans have higher levels of acquiescent responses or social desirability (i.e., tendency of survey respondents to answer questions in a manner that will be viewed favorably by others). Consistent with this perspective, previous research has found that acquiescence differs across Latino ethnic subgroups in the US [55] and that Mexicans generally demonstrate a strong desire to please others and seek approval [56].

Support could also be expected to be more favorable among countries where these kind of interventions have already been adopted, as it has been shown that policies tend to become more acceptable after they have been implemented [32]. Interestingly, support for healthy checkouts was highest in Mexico despite retailers in the UK making significant progress in this area [16]. This finding may also be related to an increased awareness of the need for action to tackle the current epidemic of obesity and diabetes in Mexico [57]. Furthermore, while Mexico is undergoing a radical transformation in its food system and diet away from its indigenous roots, public markets, street markets and informal retailers continue to be principal actors in urban food provisioning despite the incursion of corporate retailers [58]. Nevertheless, it is noteworthy that the Mexico sample had notably higher levels of education than census estimates, so the distortion of observed estimates due to residual confounding by high education cannot be ruled out.

\section{Differences within countries}

Overall, respondents who were older, female, highly educated, and reported having more nutrition knowledge tended to be more supportive of the supermarket initiatives.

Several explanations have been proposed for the greater support observed among certain demographic sub-groups, such as increased health consciousness among women and enhanced awareness of the burden of disease with age [32]. Similarly, an individual's awareness and experience of harm associated with the target behavior also seems to influence support [32]. For instance, knowledge of harm has been found to increase support for policies designed to restrict smoking and second-hand smoke. In this study, there was a statistically significant direct association between nutrition knowledge and support for healthy supermarket-led initiatives. Exploratory analyses (not shown) suggested that those participants aware of the link between consumption 
of sugary drinks/ food high in sugar, and increased risk of chronic health conditions like obesity and diabetes, were significantly more likely to support all initiatives. Respondents' own behavior, health and experience have also been consistently associated with support, being highest among those whose habits are not discouraged [32]. Although self-reported consumption of SSB and FV did not substantially alter the results when included as covariates in logistic regression models, participants with less healthy dietary habits (i.e., high SSB and low FV consumption) were found to be more likely to reject interventions that aim to discourage these habits. This finding is consistent with previous evidence showing that self-interest is an important predictor of individual preferences for interventions [32].

Additionally, having a higher BMI was marginally associated with support for fewer end-of-aisle displays containing unhealthy foods or soft drinks but not with support for other initiatives. However, a significant proportion of participants in each country did not report their BMI or were coded as missing after deleting extreme numeric values, with this group having the lowest support for all initiatives. These findings seem to contradict each other given that this set of participants often have larger body sizes [59]. Evidence regarding BMI and support for health promoting policies has also been inconsistent, with one previous study finding that those with a higher BMI were more likely to support menu labelling policies [60], and another that those with a higher BMI had less positive attitudes towards the use of food labels [61].

Statistically significant interactions were found between country and several covariates including age, sex, and self-reported nutrition knowledge, with no common trend across initiatives. This shows that country-level culture and ideology play an important role on the magnitude and direction of the association between sociodemographic characteristics and support for supermarket placement initiatives. Further studies would be required to better understand the interactions between context and individual-level factors.

\section{Strengths and limitations}

The main strengths of this study include the comparison of multiple countries based on a relatively large sample size. To our knowledge, this is the most comprehensive multi-country study exploring support for different initiatives to promote healthy food choices in supermarkets and considering a range of sociodemographic variables. It is also worth highlighting that this is the first study to assess supermarket nudges in low or middle-income countries in comparison with higher income countries. Considering that previous studies have been mainly carried out in Europe and the United States, the present study adds to the existing knowledge and sheds light on the public health relevance of these kind of initiatives in Latin America. However, some limitations should be acknowledged. Firstly, we only assessed support for three initiatives focused on product placement. Given the broad scope of the IFPS, which assesses many different domains related to dietary patterns and policy-relevant behaviors, it was only possible to include a very limited number of questions regarding support for supermarket policies within the retail environment section of the survey. A broader set of different types of interventions (e.g., based on education, price, food labelling, etc.) should be explored in future studies in order to better understand which types of retailer interventions are likely to attract more support. Also, this study did not assess whether support varied depending on whether the intervention is led by supermarkets or regulated by governments; this area warrants further investigation. Although sampling weights were applied, the sample cannot be considered to be nationally representative as respondents were recruited using non-probability-based sampling. For example, the study sample differed from the general population across the five countries with a somewhat lower proportion of self-reported overweight and obese individuals compared to national estimates. Moreover, as mentioned earlier, the Mexican recruitment panel had few available subjects with low education so the study sample is biased toward participation of more highly educated individuals from Mexico. All self-reported data are subject to inherent measurement error. Nevertheless, all were derived from previously published instruments. Lastly, given the snapshot nature of cross-sectional studies, we cannot establish causality for any association. Even though this study design is appropriate for determining the current level of support for supermarket interventions among demographic subgroups and how it varies between countries, comparisons using repeated measures from future waves of the IFPS study will be insightful to evaluate changes over time, particularly in light of any country-specific changes in supermarket layouts or policies.

\section{Implications}

This large, multi-country study represents a unique opportunity to assess the support for different healthy food retail initiatives in the supermarket setting. Although we were only able to assess a limited range of initiatives in this survey, the results confirm that the majority of respondents supported supermarket initiatives focused on product placement and, in particular, greater shelf space for fruits and vegetables. In most contexts, there could be an opportunity to further increase support by targeting customers' nutrition knowledge. This evidence can be used by governments, public health groups and civil 
society organizations to advocate for healthier supermarket food environments, and should also encourage supermarkets to innovate in this regard. Local consultation with retailers may be helpful to understand the degree to which these findings could feasibly influence their marketing practices.

\section{Conclusions}

Although support varied somewhat based on the type of initiative, the cultural context of countries and individual sociodemographic characteristics, most people in the five included countries supported supermarket initiatives focused on product placement. This evidence should be used to support efforts by retailers and policy makers to implement healthy food retail strategies including healthier checkouts and end-of-aisle displays, as well as increased shelf space for fruit and vegetables.

\section{Abbreviations}

BMI: Body Mass Index; FV: Fruits and Vegetables; IFPS: International Food Policy Study; UK: United Kingdom; US: United States

\section{Supplementary Information}

The online version contains supplementary material available at https://doi. org/10.1186/s12966-021-01149-0.

Additional file 1: Supplementary Table 1. Characteristics of the overall analytic sample vs. those with missing values (not asked) in each supermarket initiative support question. International Food Policy Study $2018(n=22,264)$. Unweighted.

Additional file 2: Supplementary Table 2. Weighted proportion (\%) of 'support' (S), 'neutral' (N) and 'oppose' (O) responses to supermarket initiatives in the total sample and by country. International Food Policy Study $2018(n=22,264)$.

Additional file 3: Supplementary Table 3. Adjusted OR* (95\% Cl) of characteristics associated with support for supermarket initiatives focused on product placement - excluding respondents that selected 'neutral'. International Food Policy Study 2018.

Additional file 4: Supplementary Table 4. Adjusted $\mathrm{OR}^{*}(95 \% \mathrm{Cl})$ of characteristics associated with support for supermarket initiatives focused on product placement - including dietary variables. International Food Policy Study 2018.

Additional file 5: Supplementary Table 5. Adjusted $\mathrm{OR}^{*}(95 \% \mathrm{Cl})$ of characteristics associated with support for supermarket initiatives stratified by countries. International Food Policy Study 2018.

\section{Acknowledgements}

The authors would like to thank the participants from the 2018 International Food Policy Study, as well as the research assistants who were fundamental in surveying and data collection.

\section{Authors' contributions}

$\mathrm{DH}$ conceived, designed and executed the International Food Policy Study. $\mathrm{DH}, \mathrm{CMW}$ and LV recruited participants, and collected and managed data. $\mathrm{DH}, \mathrm{CMW}, \mathrm{LV}, \mathrm{GS}$ and AJC contributed to the survey development. CGD, GS and AJC conceived this study. CGD performed the statistical analysis and drafted the manuscript. AJC helped analyze and interpret data. GS, LV, DH, CMW, CN, MBR and AJC revised the manuscript critically for intellectual content. All authors read and approved the final manuscript.

\section{Funding}

Funding for this project was provided by a Canadian Institutes of Health Research (CIHR) Project Grant, with additional support from an International
Health Grant, the Public Health Agency of Canada (PHAC), and a CIHR PHAC Applied Public Health Chair (Hammond). Gómez-Donoso was supported by a predoctoral contract for training in health research of the Instituto de Salud Carlos III and a mobility grant from the Navarra (Spain) Regional Government. The funders had no role in study design, data collection and analysis, decision to publish, or preparation of the manuscript.

Availability of data and materials

The datasets used and/or analyzed during the current study are available from the corresponding author on reasonable request.

\section{Declarations}

\section{Ethics approval and consent to participate}

The study was reviewed by and received ethics clearance through a University of Waterloo Research Ethics Committee (Office of Research Ethics \#30829) prior to data collection. A full description of the study methods can be found in the International Food Policy Study: Technical Report - Wave 2 (2018) at www.foodpolicystudy.com/methods. All participants were provided with information about the study and were asked to provide consent before participating.

\section{Consent for publication}

Not applicable.

\section{Competing interests}

The authors declare that they have no competing interests.

\section{Author details}

'Department of Preventive Medicine and Public Health, School of Medicine, University of Navarra, Pamplona, Spain. ${ }^{2}$ Biomedical Research Centre Network on Physiopathology of Obesity and Nutrition (CIBERobn), Institute of Health Carlos III, Madrid, Spain. ${ }^{3}$ Global Obesity Centre (GLOBE), Institute for Health Transformation, Deakin University, 221 Burwood Highway, Burwood VIC, Geelong 3125, Australia. ${ }^{4}$ Centre Nutrition, Santé et Société (NUTRISS), Institut sur la nutrition et les aliments fonctionnels, École de nutrition, Université Laval, Québec, Canada. ${ }^{5}$ School of Public Health and Health Systems, University of Waterloo, Waterloo, Canada. ${ }^{6}$ Centro de Investigación en Nutrición y Salud, Instituto Nacional de Salud Pública, Cuernavaca, Mexico.

Received: 8 October 2020 Accepted: 2 June 2021

Published online: 14 June 2021

\section{References}

1. Global Burden of Disease 2017 Diet Collaborators. Health effects of dietary risks in 195 countries, 1990-2017: a systematic analysis for the Global Burden of Disease Study 2017. Lancet. 2019;393(10184):1958-72.

2. White M, Aguirre E, Finegood D, Holmes C, Sacks G, Smith R. What role should the commercial food system play in promoting health through better diet? BMJ. 2020;368:m545. https://doi.org/10.1136/bmj.m545.

3. Peeters A. Obesity and the future of food policies that promote healthy diets. Nat Rev Endrocrinol. 2018;14(7):430-7. https://doi.org/10.1038/s41574018-0026-0.

4. Glanz K, Bader MD, lyer S. Retail grocery store marketing strategies and obesity: an integrative review. Am J Prev Med. 2012;42(5):503-12. https:// doi.org/10.1016/j.amepre.2012.01.013.

5. Hawkes C. Dietary implications of supermarket development: a global perspective. Dev Policy Rev. 2008;26(6):657-92. https://doi.org/10.1111/j.14 67-7679.2008.00428.x.

6. Thornton LE, Cameron AJ, McNaughton SA, Worsley A, Crawford DA. The availability of snack food displays that may trigger impulse purchases in Melbourne supermarkets. BMC Public Health. 2012;12:1-8.

7. Nakamura R, Pechey R, Suhrcke M, Jebb SA, Marteau TM. Sales impact of displaying alcoholic and non-alcoholic beverages in end-of-aisle locations: an observational study. Soc Sci Med. 2014;108:68-73. https://doi.org/10.101 6/j.socscimed.2014.02.032.

8. Cameron AJ, Charlton E, Ngan WW, Sacks G. A systematic review of the effectiveness of supermarket-based interventions involving product, promotion, or place on the healthiness of consumer purchases. Curr Nutr Rep. 2016;5(3):129-38. https://doi.org/10.1007/s13668-016-0172-8. 
9. Cohen DA, Lesser LI. Obesity prevention at the point of purchase. Obes Rev. 2016;17(5):389-96. https://doi.org/10.1111/obr.12387.

10. Martin L, Bauld L, Angus K. Rapid evidence review: The impact of promotions on high fat, sugar and salt (HFSS) food and drink on consumer purchasing and consumption behavior and the effectiveness of retail environment interventions. NHS Health Scotland. 2017. http://www.hea Ithscotland.scot/media/1611/rapid-evidence-review-restriction-of-pricepromotions.pdf. Accessed 19 Feb 2020.

11. Coker T, Rumgay H, Whiteside E, Rosenberg G, Vohra J. Paying the price: New evidence on the link between price promotions, purchasing of less healthy food and drink, and overweight and obesity in Great Britain". Cancer Research UK. 2019. https://www.cancerresearchuk.org/ sites/default/files/paying_the_price___full_report.pdf. Accessed 17 Feb 2020

12. Mulrooney HM, Bell J. Does the food retail environment reflect UK public health recommendations for healthy eating? Public Healht. 2016;134:114-6. https://doi.org/10.1016/j.puhe.2015.12.004

13. Vandevijvere S, Waterlander W, Molloy J, Nattrass H, Swinburn B. Towards healthier supermarkets: a national study of in-store food availability, prominence and promotions in New Zealand. Eur J Clin Nutr. 2018;72(7): 971-8. https://doi.org/10.1038/s41430-017-0078-6.

14. Farley TA, Rice J, Bodor JN, Cohen DA, Bluthenthal RN, Rose D. Measuring the food environment: shelf space of fruits, vegetables, and snack foods in stores. J Urban Health. 2009;86(5):672-82. https://doi.org/10.1007/s11524009-9390-3.

15. Thornton LE, Cameron AJ, McNaughton SA, et al. Does the availability of snack foods in supermarkets vary internationally? Int J Behav Nutr Phys Act. 2013;10(1):56. https://doi.org/10.1186/1479-5868-10-56.

16. Ejlerskov KT, Stead M, Adamson A, White M, Adams J. The nature of UK supermarkets' policies on checkout food and associations with healthfulness and type of food displayed: cross-sectional study. Int J Behav Nutr Phys Act. 2018;15(1):52. https://doi.org/10.1186/s12966-018-0684-2.

17. Horsley JA, Absalom KAR, Akiens EM, Dunk RJ, Ferguson AM. The proportion of unhealthy foodstuffs children are exposed to at the checkout of convenience supermarkets. Public Health Nutr. 2014;17(11):2453-8. https:/ doi.org/10.1017/S1368980013003571.

18. Obesity Health Alliance. Out of place: the extent of unhealthy foods in prime locations in supermarkets. 2018. http://obesityhealthalliance.org.uk/ wp-content/uploads/2018/11/Appendix-1-report-methodology.pdf. Accessed 3 Mar 2020

19. Schultz S, Cameron AJ, Grigsby-Duffy L, Robinson E, Marshall J, Orellana L, Sacks G. Availability and placement of healthy and discretionary food in Australian supermarkets by chain and level of socio-economic disadvantage. Public Health Nutr. 2021;24(2):203-14.

20. Roger S. Omnichannel report: finding growth in reinvented retail. Available at: https://www.kantarworldpanel.com/global/News/OmnichannelreportFinding-growth-in-reinvented-retail. Accessed 3 Mar 2020.

21. Dijksterhuis A, Smith PK, Van Baaren RB, et al. The unconscious consumer: effects of environment on consumer behavior. J Consum Psychol. 2005; 15(3):193-202. https://doi.org/10.1207/s15327663jcp1503_3.

22. The Robert Wood Johnson Foundation and The Food Trust. Harnessing the Power of Supermarkets to Help Reverse the Childhood Obesity Epidemic. June 2010. Available from: thefoodtrust.org/uploads/. Accessed 5 Mar 2020

23. Holsten JE. Obesity and the community food environment: a systematic review. Public Health Nutr. 2009;12(3):397-405. https://doi.org/10.1017/S13 68980008002267.

24. Shaw SC, Ntani G, Baird J, Vogel CA. A systematic review of the influences of food store product placement on dietary-related outcomes. Nutr Rev. 2020;78(12):1030-45.

25. Sacks G, Looi E, Cameron A, Backholer K, Strugnell C, et al. Population-level strategies to support healthy weight: an Evidence Check rapid review brokered by the Sax Institute (www.saxinstitute.org.au) for Queensland Health, 2019. Accessed 10 Feb 2020.

26. Vallgårda S. Childhood obesity policies - mighty concerns, meek reactions. Obes Rev. 2018;19(3):295-301. https://doi.org/10.1111/obr.12639.

27. Lang T, Rayner G. Overcoming policy cacophony on obesity: an ecological public health framework for policymakers. Obes Rev. 2007;8(s1):165-81. https://doi.org/10.1111/j.1467-789X.2007.00338.X.

28. Kelly M, Barker M. Why changing health-related behavior is so difficult. Public Health. 2016;136:109-16. https://doi.org/10.1016/j.puhe.2016.03.030.
29. Mazzocchi M, Cagnone S, Bech-Larsen T, Niedźwiedzka B, Saba A, Shankar B, et al. What is the public appetite for healthy eating policies? Evidence from a cross-European survey. Health Econ Policy Law. 2015;10(3):267-92. https:// doi.org/10.1017/S1744133114000346.

30. Kwon J, Cameron AJ, Hammond D, et al. A multi-country survey of public support for food policies to promote healthy diets: Findings from the International Food Policy Study. BMC Public Health. 2019;19:1205.

31. Kongats K, McGetrick JA, Raine KD, Voyer C, Nykiforuk CIJ. Assessing general public and policy influencer support for healthy public policies to promote healthy eating at the population level in two Canadian provinces. Public Health Nutr. 2019;22(8):1-11.

32. Diepeveen $\mathrm{S}$, Ling T, Suhrcke M, Roland M, Marteau TM. Public acceptability of government intervention to change health-related behaviors: a systematic review and narrative synthesis. BMC Public Health. 2013;13:1-11.

33. Bos C, Lans IV, Van Rijnsoever F, Van Trijp H. Consumer acceptance of population-level intervention strategies for healthy food choices: the role of perceived effectiveness and perceived fairness. Nutrients. 2015;7(9):7842-62. https://doi.org/10.3390/nu7095370.

34. Hagmann D, Siegrist M, Hartmann C. Taxes, labels, or nudges? Public acceptance of various interventions designed to reduce sugar intake. Food Policy. 2018;79:156-65. https://doi.org/10.1016/j.foodpol.2018.06.008.

35. Thaler RH, Sunstein CR. Nudge: improving decisions about health, wealth, and happiness. New Haven, CT and London: Yale University Press; 2008.

36. Petrescu DC, Hollands GJ, Couturier DL, Ng YL, Marteau TM. Public acceptability in the UK and USA of nudging to reduce obesity: the example of reducing sugar-sweetened beverages consumption. Plos One. 2016;11(6): e0155995. https://doi.org/10.1371/journal.pone.0155995.

37. Reisch LA, Sunstein CR, Gwozdz W. Viewpoint: beyond carrots and sticks: Europeans support health nudges. Food Policy. 2017;69:1-10. https://doi. org/10.1016/j.foodpol.2017.01.007.

38. Sunstein $C R$, Reisch $L A$, Kaiser M. Trusting nudges? Lessons from an international survey. J Eur Public Policy. 2019;26(10):1417-43. https://doi. org/10.1080/13501763.2018.1531912.

39. Sunstein CR. People prefer system 2 nudges (kind of). Duke Law J. 2016;66: $121-68$.

40. Hartmann-Boyce J, Bianchi F, Piernas C, Riches SP, Frie K, Nourse R, et al. Grocery store interventions to change food purchasing behaviors: a systematic review of randomized controlled trials. Am J Clin Nutr. 2018; 107(6):1004-16. https://doi.org/10.1093/ajcn/nqy045.

41. Cullerton K, Donnet T, Lee A, Gallegos D. Playing the policy game: a review of the barriers to and enablers of nutrition policy change. Publ Health Nutr. 2016;19(14):2643-53. https://doi.org/10.1017/S1368980016000677.

42. Clarke B, Swinburn B, Sacks G. Investigating menu kilojoule labelling policy adoption from a political science perspective. Food Policy. 2019:89:101784 https://doi.org/10.1016/j.foodpol.2019.101784.

43. Hammond D, White CM, Rynard VL, Vanderlee L. International Food Policy Study: Technical Report— 2018 Survey (Wave 2); Waterloo: University of Waterloo; 2019. http://foodpolicystudy.com/methods/. Accessed 26 Mar 2020.

44. Hollands GJ, Bignardi G, Johnston M, Kelly MP, Ogilvie D, Petticrew M, et al. The TIPPME intervention typology for changing environments to change behavior. Nat Hum Behav. 2017;1 (8):0140. https://doi.org/10.1038/s41562-017-0140.

45. Hecht AA, Perez CL, Polascek M, Thorndike AN, Franckle RL, Moran AJ. Influence of food and beverage companies on retailer marketing strategies and consumer behavior. Int J Environ Res Public Health. 2020;17(20):7381. https://doi.org/10.3390/ijerph17207381.

46. Center for Science in the Public Interest. UK Retailers Rethink Checkout. April 2019. Available online: https://cspinet.org/sites/default/files/atta chment/UK\%20Healthy\%20Checkout\%20FINAL.pdf. Accessed 26 Mar 2020.

47. ALDI Australia. Healthy shopping made easy at ALDI. 2018. Available online: https://www.aldiunpacked.com.au/healthy-shopping-made-easy-at-aldi/

48. Woolworths Group. Making healthier eating easier. https://www. woolworthsgroup.com.au/page/community-and-responsibility/groupresponsibility/environment/inspiring-healthy-choices. Accessed 26 Mar 2020.

49. Hunter College New York City Food Policy Center. Berkeley Reduces Impulse Buying with Healthy Checkout Ordinance. 2020. Available online: https://www.nycfoodpolicy.org/food-policy-snapshot-berkeley-healthycheckout-ordinance/

50. Vanderlee L, Reid JL, White CM, Hobin EP, Acton RB, Jones AC, et al. Evaluation of the online beverage frequency questionnaire (BFQ). Nutr J. 2018;17(1):73. https://doi.org/10.1186/s12937-018-0380-8. 
51. Herforth A, Arimond M, Álvarez-Sánchez C, Coates J, Christianson K, Muehlhoff E. A global review of food-based dietary guidelines. Adv Nutr. 2019;10(4):590-605. https://doi.org/10.1093/advances/nmy130.

52. Kroese FM, Marchiori DR, de Ridder DT. Nudging healthy food choices: a field experiment at the train station. J Public Health (Oxf). 2016;38(2):e133-7. https://doi.org/10.1093/pubmed/fdv096.

53. Ulijaszek SJ, McLennan AK. Framing obesity in UK policy from the Blair years, 1997-2015: the persistence of individualistic approaches despite overwhelming evidence of societal and economic factors, and the need for collective responsibility. Obes Rev. 2016;17(5):397-411. https://doi.org/10.1111/obr.12386.

54. Russell C, Lawrence M, Cullerton K, Baker P. The political construction of public health nutrition problems: a framing analysis of parliamentary debates on junk-food marketing to children in Australia. Public Health Nutr. 2020:1-12.

55. Davis RE, Johnson TP, Lee $\mathrm{S}$, Werner $\mathrm{C}$. Why do Latino survey respondents acquiesce? Respondent and interviewer characteristics as determinants of cultural patterns of acquiescence among Latino survey respondents. CrossCult Res. 2019;53(1):87-115. https://doi.org/10.1177/1069397118774504.

56. Díaz-Guerrero R. Bajo las garras de la cultura. Psicología del Mexicano 2. [Under the claws of culture. In Psychology of the Mexican 2]. Trillas Editorial. 2003.

57. Barquera S, White M. Treating obesity seriously in Mexico: realizing, much too late, action must be immediate. Obesity (Silver Spring). 2018;26(10): 1530-1. https://doi.org/10.1002/oby.22296.

58. Denham D, Gladstone F. Making sense of food system transformation in Mexico. Geoforum. 2020;115:67-80. https://doi.org/10.1016/j. geoforum.2020.05.024.

59. Ramos E, Lopes C, Oliveira A, Barros H. Unawareness of weight and height the effect on self-reported prevalence of overweight in a population-based study. J Nutr Health Aging. 2009;13(4):310-4. https://doi.org/10.1007/s12603009-0028-7.

60. Bhawra J, Reid JL, White CM, Hammond D, Vanderlee L, Raine K. Are young Canadians supportive of proposed nutrition policies and regulations? An overview of policy support and the impact of socio-demographic factors on public opinion. Can J Public Health. 2018;109(4):498-505. https://doi.org/1 0.17269/s41997-018-0066-1.

61. Rodolfo M, Nayga R. Toward an understanding of consumers' perceptions of food labels. Int Food Agribusiness Manag Rev. 1999;2:29-45.

\section{Publisher's Note}

Springer Nature remains neutral with regard to jurisdictional claims in published maps and institutional affiliations.

Ready to submit your research? Choose BMC and benefit from:

- fast, convenient online submission

- thorough peer review by experienced researchers in your field

- rapid publication on acceptance

- support for research data, including large and complex data types

- gold Open Access which fosters wider collaboration and increased citations

- maximum visibility for your research: over $100 \mathrm{M}$ website views per year

At BMC, research is always in progress.

Learn more biomedcentral.com/submissions 